\title{
Application of Artificial Neural Network for Flow Stress Modelling of Steel
}

\author{
Sushant Rath ${ }^{1}$, Pinaki Talukdar ${ }^{2}$, Arujun Prasad Singh ${ }^{3}$ \\ ${ }^{1}$ Flat Rolling Group, R\&D Centre for Iron \& Steel, Steel Authority of India Linited, Ranchi, India \\ ${ }^{2}$ Forge Technology Department, National Institute of Foundry \& Forge Technology, Ranchi, India \\ ${ }^{3}$ Department of Mechanical Engg, Maharishi Markandeshwar University, Mullana, Ambala, India
}

Email address:

sushant.rath@gmail.com (S. Rath)

\section{To cite this article:}

Sushant Rath, Pinaki Talukdar, Arujun Prasad Singh. Application of Artificial Neural Network for Flow Stress Modelling of Steel. American Journal of Neural Networks and Applications. Vol. 3, No. 3, 2017, pp. 36-39. doi: 10.11648/j.ajnna.20170303.12

Received: October 27, 2017; Accepted: November 20, 2017; Published: December 14, 2017

\begin{abstract}
The hot rolling mills of steel plants are in the process of transformation from manual operation to artificial intelligence (AI) based automatic operations. Most of the mill input parameters required by the automation system are recorded from different sensors installed in the mill except the flow stress of rolled material. Generally a semi-empirical equation is used that correlate flow stress with strain, strain rate and temperature during rolling. The coefficients and exponents of the empirical equations are calculated from experimental data with parameter estimation techniques. This paper discusses the application of artificial neural network (ANN) for calculation of flow stress of material from experimental data. Experiments were conducted in a dynamic thermo-mechanical simulator to measure flow stress of steel at different strain, strain rate and temperature. The experimental data was used to calculate coefficients of empirical equations using multivariable optimization techniques. The data was also used to formulate an ANN model using feed forward network. The ANN model was trained with backpropagation algorithm. The ANN method is found to be more accurate than the semi-empirical equations for correlating the flow stress with strain, strain rate and temperature.
\end{abstract}

Keywords: Flow Stress, Steel, Artificial Neural Network, Semi-Empirical Equations

\section{Introduction}

Hot rolling is an important process in a steel plant. The operators of hot rolling mills decide draft and speed schedule of the mill using their expertise and experience. A transformation is under progress in rolling mills to replace the manual operation with artificial intelligence (AI) based operation. Online mathematical models, data-driven models and hybrid models are being formulated to calculate mill parameters accurately. However, all these models require accurate and reliable data. Most of the input parameters like material temperature, strip width, roll gap, speed, roll force, torque required for model based operation are recorded from mill sensors. However, flow stress of steel, which is an important input parameter cannot be measured online because no such sensor is available at present which can measure flow stress online during rolling process.

Semi-empirical equations, which correlate flow stress with strain, strain rate and temperature, are available in literature. Researchers like Sellars [1], Shida [2], Hatta [3] and Zyuzin [4] proposed such equations. The coefficient and exponents of these equations are calculated from experimental data using parameter estimation techniques. This paper describes three models including two semiempirical equations based models and a feed-forward artificial neural network (ANN) model developed for calculation of flow stress of material from experimental data. Experiments were conducted in a dynamic thermomechanical simulator to measure flow stress of steel at different strain, strain rate and temperature. Coefficients of semi-empirical equations were calculated using multivariable optimization techniques. ANN model was trained and validated with the experimental data. 


\section{Experimental Determination of Flow Stress}

Experiments were conducted in Gleeble-3500, a dynamic thermo mechanical simulator, for determining flow stress values of steel at different strain, strain rate and temperature. The chemical composition of steel samples is given in Table-1.

Table 1. Chemical Composition of Steel (\% of wt).

\begin{tabular}{llllllll}
\hline $\mathbf{C}$ & $\mathbf{M n}$ & $\mathbf{S i}$ & $\mathbf{S}$ & $\mathbf{P}$ & $\mathbf{A l}$ & $\mathbf{N b}$ & $\mathbf{F e}$ \\
\hline 0.16 & 1.48 & 0.22 & 0.008 & 0.027 & 0.024 & 0.049 & Balance \\
\hline
\end{tabular}

Twelve numbers of cylindrical samples of $12 \mathrm{~mm}$ diameter and $15 \mathrm{~mm}$ height were prepared. These samples are tested at 4 distinct temperatures $\left(900^{\circ} \mathrm{C}, 1000^{\circ} \mathrm{C}, 1050^{\circ} \mathrm{C}, 1100^{\circ} \mathrm{C}\right)$ each at 3 strain rates $\left(1 \mathrm{sec}^{-1}, 10 \mathrm{sec}^{-1}, 100 \mathrm{sec}^{-1}\right)$. So, there were 12 tests in total. In each test, strain values were varied between 0 to 0.6 . The flow stress vs. strain data points were recorded from the data recording system of Gleeble-3500. The number data points obtained from of each test is not same. When the speed of deformation is high, the number of data points obtained from the experiment was less and when the speed of deformation is low, the number of data points obtained from the experiment was more.

Table 2. Summary of Experimental Results of Flow Stress.

\begin{tabular}{|c|c|c|c|c|c|c|}
\hline \multirow{2}{*}{ Test ID } & \multirow{2}{*}{ Temperature $\left({ }^{\circ} \mathrm{C}\right)$} & \multirow{2}{*}{ Strain Rate $\left(\mathrm{sec}^{-1}\right)$} & \multirow{2}{*}{ Strain } & \multirow{2}{*}{ No of Data Points } & \multicolumn{2}{|c|}{ Flow Stress (MPa) } \\
\hline & & & & & Min & Max \\
\hline 1 & 900 & 1 & $0-0.6$ & 353 & 39.197 & 220.46 \\
\hline 2 & 1000 & 1 & $0-0.6$ & 354 & 39.736 & 165.66 \\
\hline 3 & 1050 & 1 & $0-0.6$ & 353 & 34.508 & 138.42 \\
\hline 4 & 1100 & 1 & $0-0.6$ & 351 & 24.47 & 113.94 \\
\hline 5 & 900 & 10 & $0-0.6$ & 74 & 53.686 & 254.29 \\
\hline 6 & 1000 & 10 & $0-0.6$ & 71 & 51.167 & 205.15 \\
\hline 7 & 1050 & 10 & $0-0.6$ & 71 & 57.58 & 171.94 \\
\hline 8 & 1100 & 10 & $0-0.6$ & 72 & 55.531 & 153.48 \\
\hline 9 & 900 & 100 & $0-0.6$ & 104 & 58.8 & 291.08 \\
\hline 10 & 1000 & 100 & $0-0.6$ & 95 & 109.28 & 247.26 \\
\hline 11 & 1050 & 100 & $0-0.6$ & 89 & 82.042 & 226.6 \\
\hline 12 & 1100 & 100 & $0-0.6$ & 92 & 15.543 & 199.15 \\
\hline
\end{tabular}

Table-2 shows the summary of experimental results obtained from 12 number of tests. The minimum and maximum values of flow stress are given in the Table. Number of data points recorded in each test is also given the table. Total number of data points from these 12 tests was found to be 2079 .

\section{Development of Semi Empirical Models}

Sellars derived a basic flow stress constitutive equation for metals from first principle using Arrhenius-type temperature sensitivity term in the form of a hyperbolic sine function given by [1],

$$
\dot{\varepsilon}=C \sinh (\alpha \sigma)^{n} e^{\frac{-Q}{R T_{A}}}
$$

where, $\mathrm{R}$ is universal gas constant, TA is the absolute temperature and $\mathrm{Q}$ is the activation energy of plastic deformation. The parameters $\mathrm{C}, \alpha, \mathrm{n}$ and $\mathrm{Q}$ are coefficients of Equation (1).

The flow stress equation relating strain, strain rate and temperature was proposed by Zyuzin [4] is given below:

$$
\sigma=A \varepsilon^{m} \dot{\mathcal{E}}^{n} e^{-p T}
$$

where, A, m, n and p are coefficients of Zyuzin's equations for the tested steel material.

To obtain the coefficients of equation (1) and equation
(2), a cost function was formulated. The cost function is root mean square error between predicted and measured flow stress values of $i^{\text {th }}$ data point. The cost function needs to be minimized to obtain the coefficients of equation (1) and (2).

$$
\text { Minimize } \mathrm{f}=\sqrt{\sum\left(\sigma^{i}-\sigma_{m}^{i}\right)^{2} / n}
$$

where $\mathrm{n}$ is the number of experimental data points, $\sigma^{i}$ is the predicted flow stress of ith datapoint and $\sigma_{m}^{i}$ is the experimentally measured flow stress of ith data point. To minimize the cost function for obtaining the coefficients, a series of multivariable optimization algorithms were used. The selected algorithms were: Powell's BOTM algorithm [5], Hooke \& Jeeves's HOOKE algorithm [5], Rosenbrock's ROSENB [5] algorithm and Genetic Algorithm (GA) [6] [7]. Four multivariable optimization algorithms namely BOTM, HOOKE, ROSENB and GA were coded into computer program in Visual Basic. Net program. Root mean square error between predicted and measured flow stress were minimized by all of these four algorithms. The values of coefficients of equations (1) and (2) obtained for lowest values of cost function from the 4 algorithms are given in Table- 3 and Table- 4 respectively.

Table 3. Estimated Material Coefficients of Equation (1).

\begin{tabular}{llll}
\hline $\mathbf{C}\left(\mathrm{sec}^{-1}\right)$ & $\alpha\left(\mathrm{MPa}^{-1}\right)$ & $\mathbf{n}$ & $\mathbf{Q}(\mathbf{K J} / \mathbf{m o l e})$ \\
\hline $1.5 \times 10^{10}$ & 0.08888 & 0.8975 & 340.9 \\
\hline
\end{tabular}


Table 4. Estimated Material Coefficients Equation (2).

\begin{tabular}{llll}
\hline $\mathbf{A}(\mathbf{M P a})$ & $\mathbf{m}$ & $\mathbf{n}$ & $\mathbf{p}$ \\
\hline 2174 & 0.145 & 0.1 & 0.00255 \\
\hline
\end{tabular}

\section{Development of Artificial Neural Network Model}

A ANN model was developed to correlate flow stress with strain, strain rate and temperature. Figure-1 shows a representative diagram which shows that the flow stress is related to stain strain rate and temperature. The ANN network is a feed-forward network. Back-propagation algorithm is used to train the network. The detailed methodology of the algorithm of the backpropagation algorithm is described in literature [8] [9].

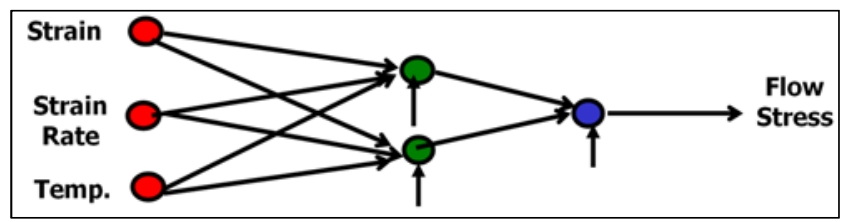

Figure 1. Typical structure of ANN Model for Flow Stress Calculation.

In the representative figure shown in Figure-1, three layers are shown. The input layer has 3 nodes, the hidden layer has two nodes and output layer has one node. Initially all the input parameters were normalized so that the values of strain, strain rate and temperature remain between 0 and 1 . The output flow stress values were also normalized so that the values remain between 0 and 1 . The transfer function for hidden nodes and output nodes were selected as "tansig" function. During training of ANN, a variable learning rate was used. The methodology is discussed in an earlier publication [10]. The number of nodes of hidden layers was changed from 2 to 3 and 4 during training of ANN.

\section{Results and Discussion}

Flow stress of were calculated using two semi-empirical equations (1) and (2) for different strain, strain rate and temperature with coefficients listed in Table- 3 and Table-4 respectively. The calculated values of flow stress were compared corresponding measured values of flow stress using a statistical parameter: square of Pearson product moment correlation coefficient (r-square). The r-square values of two empirical methods and ANN method is shown in Figure-2. In this figure, Emp1 represents the method of flow stress calculation using the semi-empirical Equation-1 and Emp2 represents method of flow stress calculation using the semi-empirical Equation-2. It is found that the r-square value between the calculated and measured flow stress values was 0.709 for equation (1) and 0.959 for equation (2). Equation (1) is less accurate than equation (2) because the strain term is not incorporated in the equation (1). The $r-$ square value for the ANN model predicted output was found to be 0.984 after a large number of training and simulations of ANN model with different number nodes $(2,3,4)$ of hidden layer and variable learning rates. A similar model of flow stress of aluminum alloy was carried out by Quan et al [11]. They have used a 3-5-5-1 BP-ANN network structure to get high accuracy. The present work has the advantage of lesser number of hidden nodes to obtain a comparable accuracy.

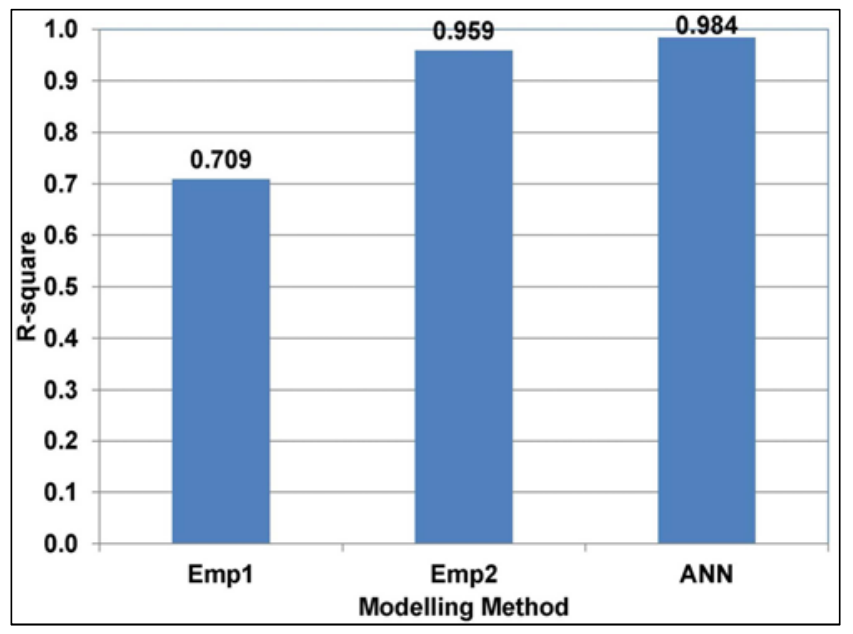

Figure 2. Comparison of performance of different modelling methods for calculation of flow stress.

The values of flow stress calculated by ANN model and measured in Gleeble-3500 for strain rate $1 \mathrm{sec}^{-1}$ is shown in Figure-3. The dotted points shows the experimental values of flow stress and the continuous line shows the flow stress calculated by the ANN model. It can be seen from the figure that there is closeness between the predicted and measured values of flow stress.

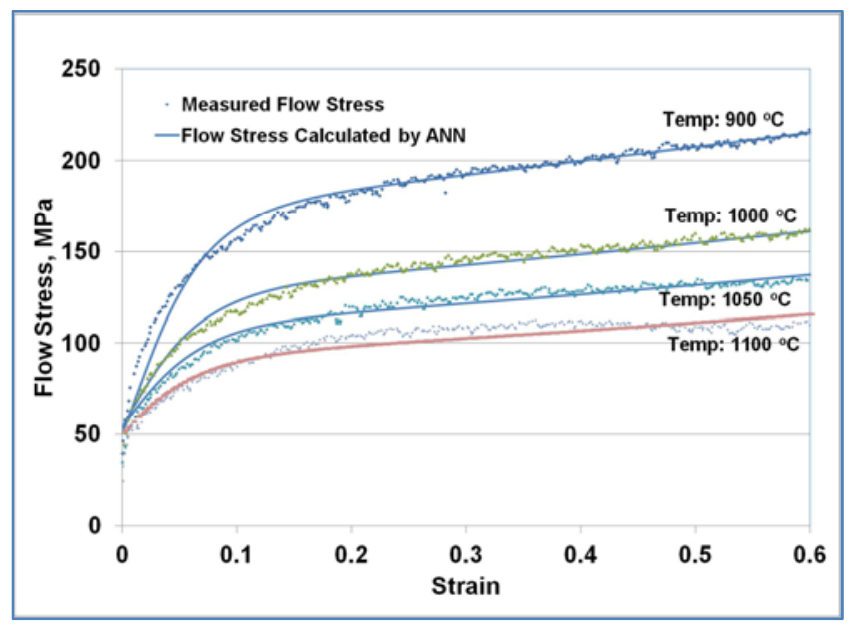

Figure 3. Measured and ANN Model calculated Flow Stress at strain rate = $1 \sec ^{-1}$.

Similarly, the values of flow stress calculated by ANN model and measured in Gleeble-3500 for strain rate $10 \mathrm{sec}^{-1}$ and $100 \mathrm{sec}^{-1}$ are shown in Figure-4 and Figure-5 respectively. It can be seen from the figures that there is closeness between the predicted and measured values of flow stress. The ANN model is more accurate than semi-empirical 
model because the non-linearity in the experimental data is well addressed in the ANN model.

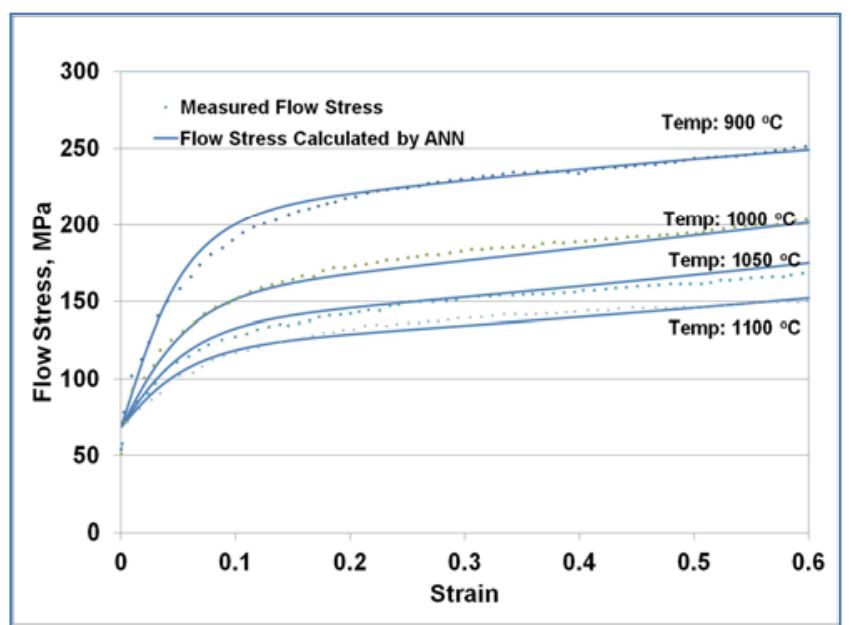

Figure 4. Measured and ANN Model calculated Flow Stress at strain rate = $100 \mathrm{sec}^{-1}$.

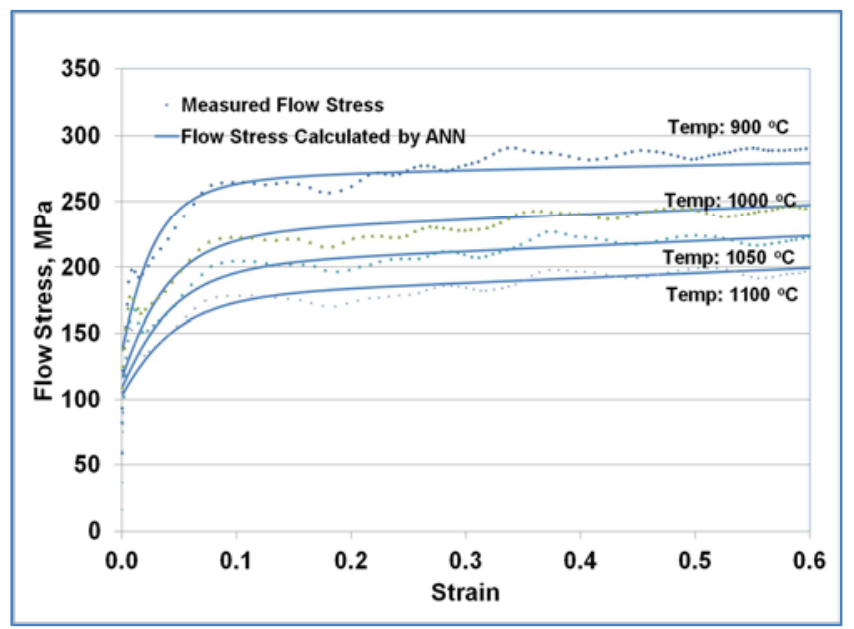

Figure 5. Measured and ANN Model calculated Flow Stress at strain rate = $10 \mathrm{sec}^{-1}$.

\section{Conclusions}

The traditional semi-empirical equation based models for calculation of flow stress of material at different strain, strain rate and temperature have been replaced by ANN based model. The model is more accurate than the semi-empirical equation based models. It is also found that there is close match between the calculated flow stress at different strain, strain rate and temperature.

\section{References}

[1] Lenard, J. G., Pietrzyk, M. and Cser, L., "Mathematical and physical simulation of the properties of hot rolled products", ELSEVIER, 1999.

[2] Shida, S. "Effect of carbon content, temperature and strain rate on compressive flow stress of carbon steel", Hitachi Research Lab Report, pp. 1-9, 1974.

[3] Hatta, N, Kakao, J, Kikuchi, S. and Takuda H, "Modelling of flow stress of plain carbon steel at elevated temperature", Steel Research, Vo. 56, pp. 572-582, 1985.

[4] Y. V. Konovalov, A. L. Ostapenko, V. E. Ponomarev, "Расчет Параметров Листовой Прокатки", Москва Металлурия (Calculation of Sheet Rolling Parameters, Moscow Metallurgy), 1986, pp. 8-27.

[5] Kuesta, J. L. \& Mize, J. H., "Optimization techniques with FORTRAN”, McGraw Hill Book Company, 1973.

[6] Belegundu, A. D. and Chandruptla, T. R., "Optimization concepts and application in Engineering", Pearson Education, 2002.

[7] Deb, K. "Optimization of Engineering Design: Algorithm and Examples”, Prentice-Hall of India, 1995.

[8] Yagnarayana, B., "Artificial Neural Networks", Prentice-Hall of India, 2004.

[9] Kriti Priya Gupta, Madhu Jain. Performance Analysis of Cellular Radio System Using Artificial Neural Networks. American Journal of Neural Networks and Applications. Vol. 3, No. 1, 2017, pp. 5-13. doi: 10.11648/j.ajnna.20170301.12.

[10] S. Rath, A. P. Singh, U. Bhaskar, B. Krishna, B. K. Santra, D. Rai and N. Neogi, "Artificial Neural Network Modeling for Prediction of Roll Force During Plate Rolling Process", International journal of Materials and Manufacturing Processes, T\&F, Volume 25, Issue 1-3, January 2010, pp. 149-153.

[11] Guo-zheng Quan, Tong Wang, Yong-le Li, Zong-yang Zhan, Yu-feng Xia, "Artificial Neural Network Modeling to Evaluate the Dynamic Flow Stress of 7050 Aluminum Alloy", J. of Materi Eng and Perform (2016) 25: 553. https://doi.org/10.1007/s11665-016-1884-z. 